Preprint of a paper published by American Journal of Agricultural Economics, 99(1):123-139. Published version is available at DOI: $10.1093 /$ ajae/aaw043

\title{
Economics of controlling invasive species: a stochastic optimization model for a spatial-dynamic process
}

\author{
Morteza Chalak ${ }^{1}$, Maksym Polyakov and David J. Pannell
}

Abstract. We analyze the dynamic process of invasive-species control in a spatially explicit and stochastic setting. An integer optimization model is applied to identify optimal strategies to deal with invasive species at steady state. Optimal strategies depend on the spatial location of invasion as well as on stochastic characteristics of spread and control. Previous studies of invasive-species control have been stochastic or spatial but not both. We model a landscape as consisting of multiple cells, each of which may be subject to border control or eradication within the cell. Optimal strategies from the model are characterized as eradication, containment or abandonment of control. Representing the rate of species spread as stochastic rather than deterministic results in less-intensive control becoming optimal at equilibrium. The optimal strategy may switch from eradication to containment or from containment to abandonment. If an infestation occurs at the boundary of the region within which it may spread, it is more likely to be optimal to eradicate or contain the species, compared to an infestation in the interior of the region. If the effectiveness of border control is stochastic, then containment is not feasible in the long term, but it is still optimal as a temporary measure in some scenarios.

Keywords: Dynamics; Invasive species; Optimal control; Spatially explicit; Stochastic

JEL code: Q570

\footnotetext{
${ }^{1}$ Morteza Chalak is an assistant professor, (research) Maksym Polyakov is an assistant professor (research), and David J. Pannell is Director and Winthrop Professor, all in the Centre for Environmental Economics and Policy, School of Agricultural and Resource Economics, University of Western Australia. This research was conducted with the support of funding from the Australian Research Council Centre of Excellence for Environmental Decisions and the Australian National Environmental Research Program's Environmental Decisions Hub. The authors appreciate helpful comments provided by Rebecca Epanchin-Niell and Jim Wilen. The authors also thank two anonymous referees for their comments. Correspondence may be sent to: morteza.chalak@uwa.edu.au.
} 
Invasive species are significant threats to biodiversity, natural ecosystems and agriculture, leading to major economic and environmental damage worldwide (Costello et al. 2007; Olson and Roy 2010). Most economic studies have analyzed temporal aspects of the invasive-species control while ignoring its spatial and stochastic aspects (e.g., Saphores 2000; Chalak and Pannell 2012; Aadland, Sims, and Finnoff 2015). However, the spread of invasive species is a stochastic process over time and space. Therefore, it may be important to consider stochastic and spatial aspects as well as temporal aspects of invasive-species control.

There have not been many attempts to optimize spatially explicit dynamic processes in the economics literature (Epanchin-Niell and Wilen 2012). Exceptions include Brock and Xepapadeas (2004) and Brock and Xepapadeas (2008), who used partial differential equations to address spatial aspects of spread processes, Sanchirico and Wilen (2005 and 2007), who used integer programming to analyze spatial systems with discrete space and continuous time, and Costello and Polasky (2008), who analyzed a fishery system using dynamic programming with discrete time and space. In relation to the latter study, we note that modelling of renewable resources such as fish stocks may not provide useful guidance on invasive species management, because it focuses on interior solutions for harvest, whereas an important potential strategy for invasive species is eradication which involves corner solution. Eradication removes the damages and control is applied in finite time. Therefore a comparison between finite and infinite solutions is required (Epanchin-Niell and Wilen 2012; Wilen 2007).

Even though there have been a number of spatially-explicit studies of invasive species problems by ecologists (e.g. Latimer et al. 2009), most economic studies ignore spatial aspects and focus on the performance of particular management strategies (e.g. Burnett, Kaiser, and Roumasset 2007; Odom et al. 2003; Olson and Roy 2002). The studies that apply spatially explicit optimization models for invasive species control generally use deterministic methods (e.g. Bhat and Lenhart 1992; 
Bhat, Huffaker, and S.M. Lenhart. 1993; Hof 1998; Ding et al. 2007; Huffaker, Potapov and Lewis 2008; Albers, Fischer, and Sanchirico 2010; Finnoff, Potapov, and Lewis 2010; Sanchirico, Albers, and Fischer 2010; Epanchin-Niell and Wilen 2012). Most of these studies either analyze systems where they do not include eradication as a control option (to ensure interior solutions) or analyze very simplified systems. Aadland, Sims and Finnoff (2015) analyzed approximately optimal linear management decision under rational expectations, accounting for both temporal and spatial dynamics. They analyzed how different harvesting rules for a forest affect the outbreak of insects. Focusing on the impact of harvesting forest on the insect pest, they ignored direct pest control methods. To our knowledge, Epanchin-Niell and Wilen (2012) is the only study that has optimized spatial and dynamic solutions including eradication as a control option.

Many authors have emphasized the importance of accounting for stochasticity when analyzing the management of invasive species (e.g. Higgins, Richardson and Cowling 2000; Eiswerth and van Kooten 2002; Grevstad 2005; Bogich and Shea 2008; Hyder, Leung, and Miao 2008). These studies mainly account for stochasticity of spread of the invasive species and ignore the stochasticity of control methods. In addition, although they include stochasticity, they tend to omit spatial-dynamics of the pest.

To address these gaps in the literature, we analyze a spatially explicit dynamic process of pest invasion and control where both spread and control of invasive species are stochastic. We show how accounting for stochasticity can influence optimal control strategies in a spatially explicit model. The main aim of this paper is to analyze the relationship between economic parameters and stochastic and spatial characteristics of infestation and control. We tackle the challenging task of developing 
a spatial dynamic model of invasive-species control and dealing with uncertainty in a numerical model that builds on the work of Epanchin-Niell and Wilen (2012).

We show that if an infestation occurs at the boundary of the region, it is more likely to be optimal to eradicate or contain the species, compared to an infestation in the interior of the region. If the effectiveness of border control is stochastic, then containment is not feasible in the long run, but it is still optimal as a temporary measure in some scenarios. This paper is the first to attempt to solve a stochastic, dynamic and spatially explicit optimization model for the control of invasive species. It provides insights about the effect of stochasticity that are additional to those provided by the previous deterministic models (e.g. Epanchin-Niell and Wilen 2012).

\section{Method}

\section{Modelling biological spread and economics}

We develop a stochastic and spatially explicit dynamic optimization model. A series of square cells represent the landscape where invasion in each cell can spread to the neighboring cell and eventually can cover the entire landscape.

In a landscape with $i \times j$ cells, cells are presented as $a_{i, j}$. If the cell is invaded with a pest species, $a_{i, j}=1$, and if the cell is not invaded, $a_{i, j}=0$. Without any control, the neighboring cells of an invaded cell will be infested with some probability in the next time period. If, in year $t$, for example, cell $a_{i, j}$ is infested, in year $t+1$ cells $a_{i, j+1}$, $a_{i, j-1,} a_{i+1, j}$ and $a_{i-1, j}$ may be invaded with a certain probability.

Total economic damage caused by the invasive species depends on the number of infested cells. Damage to each cell is represented by $d$. Thus, the economic damage in the landscape in period $t$ is equal to $d \times$ number of infested cells in this period. There are two control costs: cell-control cost $(c c)$ and border-control cost $(b c)$. Cell- 
control cost refers to the cost of removing infestation from an infested cell. When a cell is infested, it will remain infested unless the infestation is removed by cell control, after which it will remain uninfested unless it is infested from a neighboring cell. Border-control cost $(b c)$ refers to the cost of preventing a cell being infested from its neighbors through their shared boundary. Each cell has 4 boundaries with neighboring cells and the border-control cost for each cell in each period is $b c \times$ number of boundaries with cells that are not infested. When the decision is to apply border or cell control, control costs are incurred even if the control is not effective.

We solve the model considering three stochastic processes which are: spread, cell control and border control. We assign separate probabilities to each of these processes to present high and low probabilities of successful cell control, border control and spread.

Each cell is either invaded or clear at the end of period (year) $t$. A decision (abandon, cell control or border control) is taken in year $t+1$. In year $t+1$, an uninvaded cell will be invaded with a particular probability if in year $t$ it had an infested neighbor and an effective border control has not been applied to the relevant border.

\section{Optimization model}

We minimize net present value of the damages caused by invasion plus control costs in an optimization framework.

The optimization model is:

$$
\operatorname{Min} \sum_{t \in T, t>0} \delta_{t}\left(\sum_{(i, j, m) \in C_{t}} a_{i, j, m, t} d+\sum_{(i, j, m) \in C} c_{i, j, m, t} c c+\sum_{(i, j, k, l) \in N} b_{i, j, k, l, m, t} b c\right)
$$


subject to

$$
\begin{array}{lr}
a_{i, j, m, 0}=a_{i, j, m} & \forall(i, j, m) \in C \\
c_{i, j, m, 0}=0 & \forall(i, j, m) \in C \\
b_{i, j, k, l, m, 0}=0 & \forall(i, j, k, l, m) \in N \\
a_{i, j, m, t} \geq a_{i, j, m, t-1}-c_{i, j, m, t} \xi_{i, j, m, t} & \forall(i, j, m) \in C, t \in T, t \geq 1 \\
a_{i, j, m, t} \geq a_{k, l, m, t-1} \phi_{i, j, m, t-1}-b_{i, j, k, l, m, t} \psi_{i, j, k, l, m, t}-c_{i, j, m, t} \xi_{i, j, m, t} & \forall(i, j, k, l, m) \in N, t \in T, t \geq 1 \\
a_{i, j, m, t} \in\{0,1\} & \forall(i, j, m) \in C, t \in T
\end{array}
$$

where $(i, j, m) \in C, i$ indexes row, $j$ indexes the column and $m$ represents the stochastic dimension in a rectangular set of cells $(C)$. Realizations of the stochastic variables (i.e. spread, border control and cell control) are presented in dimension $m$, where for each $m$ the model draws an independent random number from a continuous uniform probability distribution. $(i, j, k, l, m) \in N$, represents matches of neighboring cells, where $(i, j, m) \in C$ is the source cell and $(k, l, m) \in C$ is one of its neighbors. $t$ represents time (year) and $T$ is the number of years considered. $a_{i, j, m, t}$ represents the state of cell $(i, j, m)$ in row $i$, column $j$, stochastic dimension $m$ at time $t$. When a cell is invaded, $a_{i, j, m, t}=1$, otherwise $a_{i, j, m, t}=0 . c_{i, j, m, t}$ is a binary decision variable to remove the pest from cell $a_{i, j, m}$ in time $t . c_{i, j, m, t}=1$ if the decision is to remove invasion and $c_{i, j, m, t}=0$ otherwise. $b_{i, j, k, l, m, t}$ is a binary decision variable to control the spread of invasion along the border between $a_{i, j}$ and $a_{k, l}$ in stochastic dimension $m$ and period $t$. $b_{i, j, k, l, m, t}=1$ if the border control is applied and $b_{i, j, k, l, m, t}=0$ otherwise. $a_{i, j, m} \in\{0,1\}$ is the initial state of invasion when $\mathrm{t}=0$. The values of the decision variables are equal for $m$ in the first period. 
We introduce $\Phi_{i, j, m, t}, \Xi_{i, j, m, t}$ and $\Psi_{i, j, k, l, m, t}$ as the three multipliers that indicate the success of spread, border control and cell control, respectively. The value of these multipliers depends on the state of nature each with a known probability of occurrence resulting in value of 0 or 1 . For these we have:

$$
\begin{aligned}
& \operatorname{Pr}\left(\Phi_{i, j, m, t}=\phi_{i, j, m, t, h}\right)=p_{i, j, m, t, h}^{\phi} \\
& \operatorname{Pr}\left(\Xi_{i, j, m, t}=\xi_{i, j, m, t, h}\right)=p_{i, j, m, t, h}^{\zeta} \\
& \operatorname{Pr}\left(\Psi_{i, j, k, l, m, t}=\psi_{i, j, k, l, m, t, h}\right)=p_{i, j, k, l, m, t, h}^{\psi},
\end{aligned}
$$

which are, respectively, the probability that the multiplier for spread $\left(\Phi_{i, j, m, t}\right)$ takes the value $\phi_{i, j, m, t, h}$, that the multiplier for cell control $\left(\Xi_{i, j, m, t}\right)$ takes the value $\xi_{i, j, m, t, h}$ and that the multiplier for border control $\left(\Psi_{i, j, k, l, m, t}\right)$ takes the value $\psi_{i, j, k, l, m, t, h}$, for the states of nature $(1, \ldots, H)$.

Parameters $\phi_{i, j, m, t, h}, \xi_{i, j, m, t, h}, \psi_{i, j, k, l, m, t, h}$ are realizations for the multipliers of spread, cell control and border control, respectively. For these realizations

$$
\begin{aligned}
& \sum_{h=1}^{H} p_{i, j, m, t, h}^{\phi}=1 \\
& \sum_{h=1}^{H} p_{i, j, m, t, h}^{\xi}=1 \\
& \sum_{h=1}^{H} p_{i, j, k, l, m, t, h}^{\psi}=1 .
\end{aligned}
$$

For each multiplier, we investigate 3 probability assumptions. Table 1 provides a list of probability assumptions for each state of nature where probability of successful spread, border control or cell control are set at $1,0.8$ and 0.2 for state of nature 1 $(h=1)$. As each stochastic variable (spread, cell control and border control), has two independent states of nature, there are $8(2 \times 2 \times 2)$ states of nature in total. 
For each stochastic variable, we explore three sets of probabilities in the analysis: (1, $0),(0.8,0.2)$ and $(0.2,0.8)$. For example, we explore cases where the annual probability of spread between neighboring cells is $1,0.8$ or 0.2 . The probabilities 0.8 and 0.2 were chosen because they are both realistic in particular cases, and they can give substantially different model results. Although these probabilities do not cover the full spectrum of probability ranges, they are judged to provide good representation of high and low probabilities. We found that increasing the probability above 0.8 or decreasing it below 0.2 did not alter the optimal long-run strategy. We also found that having very small probabilities provides the same results but needs the model to be run for longer period in order to converge to equilibrium.

Table 1. Assumptions for probability of spread $\left(p_{i, j, m, t, h}^{\phi}\right)$, cell control $\left(p_{i, j, m, t, h}^{\xi}\right)$ and border control $\left(p_{i, j, k, l, m, t, h}^{\psi}\right)$ for two states of nature.

\begin{tabular}{|c|c|c|c|c|}
\hline \multirow{2}{*}{$\begin{array}{l}\text { Probability } \\
\text { assumptions }\end{array}$} & \multirow{2}{*}{$\begin{array}{l}\text { State of } \\
\text { nature }\end{array}$} & \multicolumn{3}{|c|}{ Probabilities for } \\
\hline & & $\begin{array}{c}\text { Spread } \\
\left(p_{i, j, m, t, h}^{\phi}\right)\end{array}$ & $\begin{array}{c}\text { Cell control } \\
\left(p_{i, j, m, t, h}^{\xi}\right)\end{array}$ & $\begin{array}{c}\text { Border control } \\
\left(p_{i, j, k, l, m, t, h}^{\psi}\right)\end{array}$ \\
\hline \multirow[t]{2}{*}{1} & $h=1$ & 1 & 1 & 1 \\
\hline & $h=2$ & 0 & 0 & 0 \\
\hline \multirow[t]{2}{*}{2} & $h=1$ & 0.8 & 0.8 & 0.8 \\
\hline & $h=2$ & 0.2 & 0.2 & 0.2 \\
\hline \multirow[t]{2}{*}{3} & $h=1$ & 0.2 & 0.2 & 0.2 \\
\hline & $h=2$ & 0.8 & 0.8 & 0.8 \\
\hline
\end{tabular}

In equation (1), $\delta$ is the real discount factor at time $\mathrm{t}(t \geq 0) . \delta=\frac{1}{(1+r)^{t-1}}$ where $r$ is real discount rate $^{2}, d$ is the economic damages caused by invasive species for each cell in year $t, c c$ is cell-control cost, representing the cost of removing the pest from a

\footnotetext{
${ }^{2}$ We chose $5 \%$ the discount rate which is used for evaluation of environmental and conventional capital formation (Manne 1999; Nordhaus 1994). Selecting a lower discount rate for the cases where the model is run for longer time period did not affect the optimal strategies at steady states.
} 
cell, and $b c$ is border-control cost, representing the cost of avoiding pest spread between neighboring cells.

Equation (2) indicates initial infestation in year $t_{0}$. Equations (3) and (4) show that cell control and border control start in the next time period. We chose a landscape with $9 \times 9$ dimensions. Given high computational effort needed to solve the model, choosing a larger size landscape was infeasible. Equation (5) shows that a cell that has been invaded in year $t-1$ will be invaded in year $t$ unless a cell control measure is applied and the multiplier indicating effectiveness of cell control $\left(\Xi_{i, j, m, t}\right)$ is 1 . Equation (6) shows that cell $a_{i, j, m}$ is invaded at time $t$, if it had an invaded neighbor at time $t-1$ and the multiplier indicating success of spread for at least one relevant boundary of its infested neighbors $\left(\Phi_{i, j, m, t}\right)$ takes the value 1 . However, the spread will not occur if cell control is applied and the multiplier indicating effectiveness of cell control $\left(\Xi_{i, j, m, t}\right)$ gets the value 1. Spread also would not occur if border control is applied along the relevant border and the multiplier indicating effectiveness of border control ( $\left.\Psi_{i, j, k, l, m, t}\right)$ get the value 1 .

The problem is solved for a finite time horizon using Bellman's principle of optimality. When solving for an infinite time horizon, the system can reach a steady state. However, this is not the case in a finite time horizon where the system can reach the steady state and depart from it and reach it again. To solve this problem, we lock in the steady state equilibrium using constraints after the steady state has been reached. To do this, a terminal value function has been added that accounts for economic values (damages and control costs) after the fixed time horizon.

$a_{i, j, m, t}=a_{i, j, m, t_{-} \text {mid }} \quad \forall(i, j, m) \in C, t \in T, t>t_{-} m$ 
where $t$ mid is smaller than $T$. We allow enough time for the steady state to be reached before $t \_$mid and $T$.

The terminal value calculated from the following equation (Epanchin-Niell and Wilen 2012) is added to the objective function:

$$
\sum_{t=T+1}^{\infty} \delta_{t}\left(\sum_{(i, j, m) \in C_{t}} a_{i, j, m, T} d+\sum_{(i, j, m) \in C} c_{i, j, m, T} c c+\sum_{(i, j, k, l, m) \in N} b_{i, j, k, l, m, T} b c\right)
$$

The benefit of this approach is that it accounts for the departure from steady state equilibrium toward the end of time horizon by using a constraint. This also helps to account for control costs and damages after the finite time horizon.

The binary integer programming model was solved using GAMS (General Algebraic Modelling System). When $p_{i, j, k, l, m, t}^{\psi}$ is set at 0.8 or $1, T_{-} m$ and $T$, are set at 50 and 100 years respectively. However, when $p_{i, j, k, l, m, t}^{\psi}=0.2$, it takes longer for the system to reach the steady state and $t \_m$ and $T$ are set at 100 and 150 , respectively. We solved the model for all possible combinations of the states of nature.

The model provides a single long-run equilibrium over the entire space. Mixed equilibria are not possible because damages caused by invasive species are uniform across time and space and because we represent spread as occurring only between neighboring cells. At equilibrium, the optimal decision is either "no control" where invasive species spread through the entire landscape, "containment" where invasive species is contained within a space or "eradication" where invasive species is eradicated from the landscape. Realistically, damages caused by invasive species vary across the time and space, potentially resulting in mixed equilibria - a potential topic for future research.

Optimizing the spatially explicit and stochastic model needs a large computational effort and even spatially explicit deterministic models can be 
intractable depending on the size of the landscape. Epanchin-Niell and Wilen (2012) were able to find optimal solution for a $15 \times 15$ grid size in their deterministic model. The added stochastic dimension in our model significantly magnified the curse of dimensionality, and we were unable to solve the model for a landscape with more than $9 \times 9$ grid size. A smaller size landscape limits presenting results for more flexible landscape shapes.

Here we present a selection of the results obtained. To analyze how different spatial patterns of invasive species affect optimal control, optimal control solutions are analyzed when the initial invasion is in the middle, corner or the edge of the landscape. We assume that the invasive species will not grow in the area outside the modelled landscape.

\section{Probabilities and environmental factors:}

Probabilities of successful spread, cell control and border control depend on a number of environmental factors. Probability of successful spread, for example, can be significantly influences by temperature. Hartley, Harris, and Lester (2006) showed that the probability of the spread of Argentine ant was greatest where the mean daily temperature in mid-winter was $7-14{ }^{\circ} \mathrm{C}\left(62.6-57.2^{\circ} \mathrm{F}\right)$ and maximum daily temperatures during the hottest month averaged $19-30{ }^{\circ} \mathrm{C}\left(66.2-86^{\circ} \mathrm{F}\right)$. Probabilities of spread and occurrence rapidly decrease as these conditions change. Rouget and Richardson (2003) showed that a number of factors can affect the spread Acacia cyclops, Acacia saligna, and Pinus pinaster, including altitude, land use, proximity to cultivated fields, annual precipitation, annual minimum temperature, growth days, geology, and vegetation type. Acacia cyclops had a higher probability of spread in natural areas and wetlands and where the altitude was lower than $72 \mathrm{~m}$. Acacia saligna spread more rapidly where the altitude was lower than $68 \mathrm{~m}$, in quaternary 
sandy wetlands, and in natural areas. Pius pinaster, however, had a higher probability of spread when the number of growing days exceeded 119 per year, and mean annual precipitation was between 392 and $483 \mathrm{~mm}$ (15.4 to 19.0 inches). For our case we can interpret that a low suitability of circumstances for spread aligns with 0.2 probability of spread and high suitability aligns with probability of spread equivalent to 0.8 or 1 .

Madafiglio (2002) showed that the probability of successful cell control can depend on the maximum daily temperature and the growth stage of a weed. Cook, Storrie, and Medd (1999) also showed that temperature impacts the efficacy of controlling invasive species; the maximum efficacy for the control of the weed wild radish occurred at around $24{ }^{\circ} \mathrm{C}\left(75.2^{\circ} \mathrm{F}\right)$ and declined to a minimum efficacy at $8{ }^{\circ} \mathrm{C}$ $\left(46.4^{\circ} \mathrm{F}\right)$. However, they showed that soil moisture and growth stage did not significantly affect the efficacy of control. Fiori et al. (2013) showed that herbicides had high efficacy on Gonyaulax. spinifera near optimal temperature conditions (20 to $\left.25^{\circ} \mathrm{C}\right)\left(68\right.$ to $\left.77^{\circ} \mathrm{F}\right)$, while they became ineffective when temperature goes below $15^{\circ} \mathrm{C}\left(59^{\circ} \mathrm{F}\right)$. In our model, we assume that near-optimal conditions results in high probability of successful cell control (i.e. 1 or 0.8 ) while low temperature could result in the probability of successful cell control of around 0.2 .

Effectiveness of border control depends on the characteristics of the invasive species, landscapes, and the location of "border control lines" (Grice et al. 2010). Probability of successful border control is higher where invasive species has frequent reproduction, high productive output, unmanageable dispersal mechanism, long dispersal distance and large seed banks. These conditions would be most likely to align with our results for $80 \%$ efficacy of border control. Border control is also less effective (e.g. around 0.2 efficacy) where the land consists of a large area of highly 
suitable habitat for invasive species and suitable patches are highly connected (Grice 2006).

\section{Results}

\section{Optimal long-run outcomes for the deterministic case}

Here we illustrate how long-run outcomes of optimal strategies change depending on the eradication and border-control costs when the spread, border control and cell control are deterministic. These results are consistent with Epanchin-Niell and Wilen (2012) who analyzed the deterministic scenario. Three cases are considered: (1) when the initial infestation is in the middle of the landscape (Fig. 1A); (2) when the initial infestation is in the corner of the landscape (Fig. 1B); and (3) when the initial infestation is on the edge (Fig. 1C).

(A)

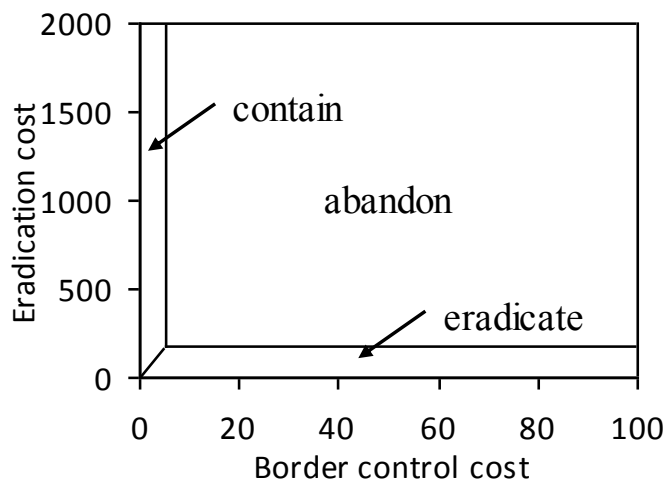

(C)

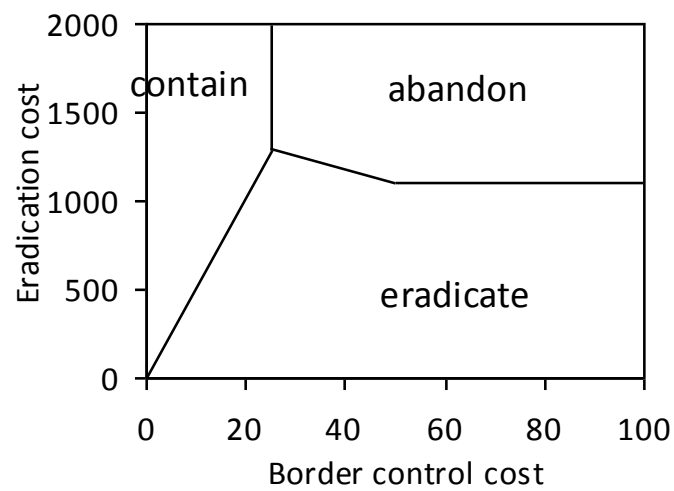

(B)

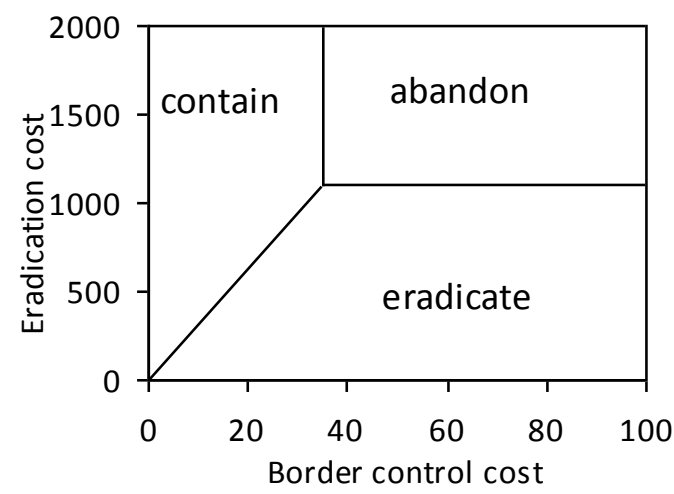

Fig. 1. Optimal long-run outcomes for the deterministic model when A) the initial infestation is in the middle, B) initial infestation is in the corner and C) initial 
infestation is on the edge of the landscape.

When both eradication and border-control costs are high, the marginal cost of control becomes larger than the marginal benefit of control at steady state, so the optimal long-run outcome is abandon ment of control. When the eradication cost is low and border-control cost is sufficiently high, the optimal long-run outcome is eradication. For all levels of eradication cost, when the border-control cost is sufficiently low, it becomes optimal to apply border control along the borders of the infested area, and the optimal long-run outcome is containment.

Clearly, the optimal strategy for controlling the invasive species depends on the spatial location of initial infestation. When the initial infestation is in the middle of the landscape, a larger number of cells will be newly infested in each period. Therefore, the infestation can spread faster in the landscape. This means that in order to eradicate, a higher control effort is required and eradication is not cost-effective except at low eradication cost. However, when the invasion is in the corner or on the edge, its rate of spread is slower (because spread to areas outside the modelled landscape is not possible) and less control effort is needed to eradicate; therefore it is optimal to eradicate or contain for a larger range of border control and cell-control costs.

The deterministic model converges to the steady state after $30-80$ years. It takes a relatively short time period for the model to reach the steady state if initial infestation is in the middle of the landscape and longer when infestation is on the edge or in the corner of the landscape. 
Optimal long-run outcomes when the probability of spread, successful cell and border control is $80 \%$

When the probabilities of spread, cell control and border control are $80 \%$, optimal long-run outcomes differ from the outcomes for the deterministic case. When efficacy of border control is stochastic, the probability that border control can stop the weed from spreading is smaller than 1. Even for very low probabilities of failure in border control, it will be a matter of time until a weed eventually crosses the border and infest the neighboring cell. Given that we analyze the optimal long-run outcomes at steady state and allow enough time for the model to converge to the equilibrium, stochastic border control always results in the spread of infestation to all neighboring cells. Therefore, in contrast with the results of deterministic case (Fig. 1A-C), containment does not appear as an optimal strategy at steady state in any of the panes of Fig. 2A-C. These findings are driven by the stochastic nature of border control.

(A)

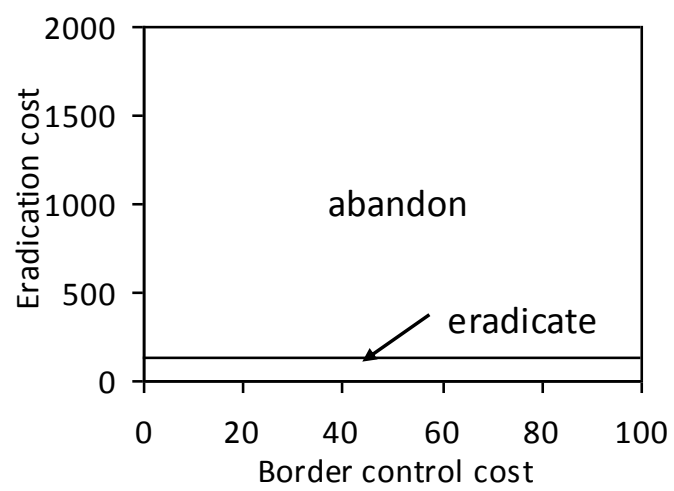

(C)

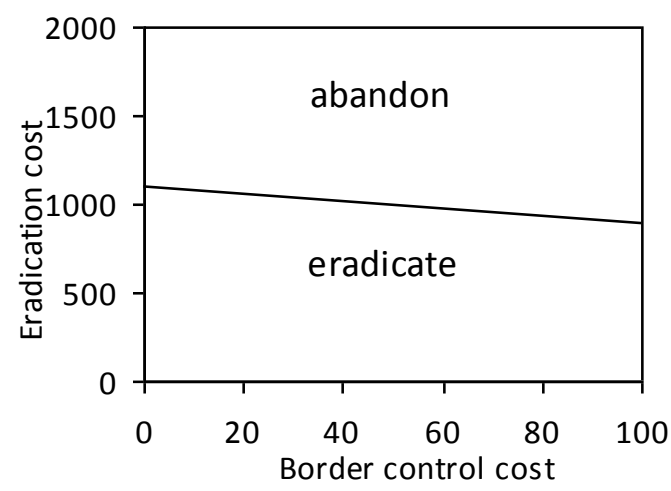

(B)

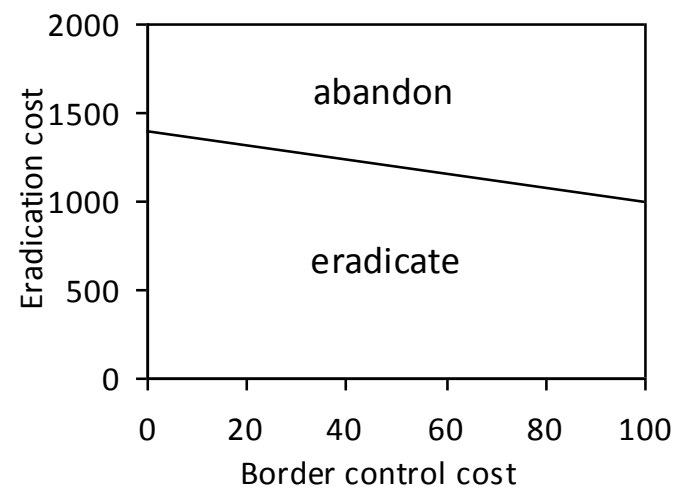


Fig. 2. Optimal long-run outcomes when the probabilities of spread, successful cell and border control are $80 \%$. The initial invasion is either in the middle (A), in the corner $(\mathrm{B})$ or on the edge of the landscape $(\mathrm{C})$.

When the initial infestation is located in the middle of the landscape (Fig. 2A), invasive species can spread to a larger number of cells as there are more surrounding uninfested cells. Therefore, a relatively high eradication effort is needed to control invasive species and it becomes optimal to eradicate only when the eradication cost is low. However, when the initial infestation is in the corner (Fig. 2B) or on the edge of the landscape (Fig. 2C), it is relatively less costly to contain the infestation, as there are fewer boundaries over which spread threatens to occur. Therefore, it is optimal to eradicate for a larger range of eradication costs. Border control together with cell control helps to deliver eradication of the invasive species. When the initial infestation is in the corner or edge of the landscape, an increase in border-control cost reduces the marginal benefit of eradication, making eradication less cost-effective (see the downward sloping lines in Fig. 2A and 2B).

When initial infestation is in the corner of the landscape rather than on the edge, it takes longer for the infestation to spread throughout the landscape because it spreads on fewer fronts. Given that the infestations that result from spread then occur later in time, their values are further discounted in time. Therefore, overall economic damages where the initial infestation is in the corner of the landscape is lower and the maximum eradication cost for which eradication is optimal is lower compared with the case where infestation is on the edge of the landscape. 
Optimal long-run outcomes when the probability of spread, and successful cell and border control is $20 \%$

Optimal long-run outcomes at steady state when the probability of spread and successful cell and border control is $20 \%$ are presented in Fig. 3A-C. As in the previous section, even when border control is applied along the borders of infested cells, the invasive species eventually spreads to neighboring cells because, as time passes, there are repeated opportunities for the border to be crossed, and sooner or later it is crossed.

Given that the success of control is low (20\%), eradication is optimal only in the most favorable case - when the initial infestation is in the corner of the landscape and eradication cost is low. When initial infestation is at the corner of the landscape, the spread of invasive species is slow because spread occurs over a smaller number of neighboring cells. This makes eradication cheaper and more cost-effective as the number of infested cells to be controlled is smaller.. Therefore, it is more likely to be optimal to control the invasive (Fig. 3B). However, when the initial infestation is in the middle or on the edge, eradication is not optimal at steady state because more control effort is needed to eradicate the invasion (Fig. 3A and 3C). Note that the optimality of eradication mainly depends on eradication cost, but also depends to some extent on the border-control cost. In other words, there is an interaction between cell control and border control. For example, in the cases when eradication is optimal, an increase in the border-control cost alone can result in replacement of eradication by abandonment of control.

\section{Figure 3}


(A)

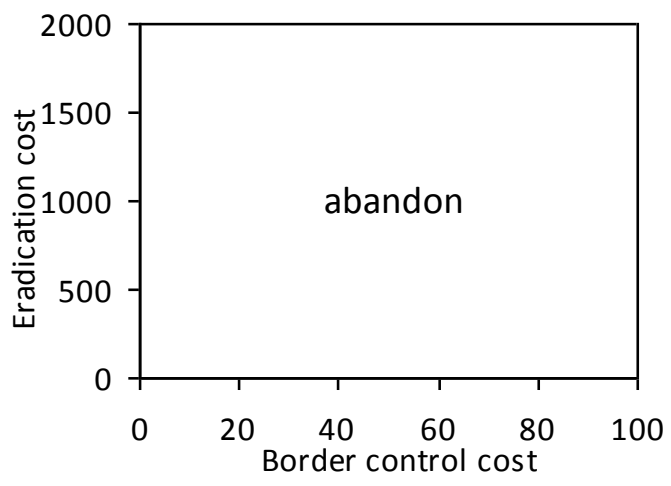

(C)

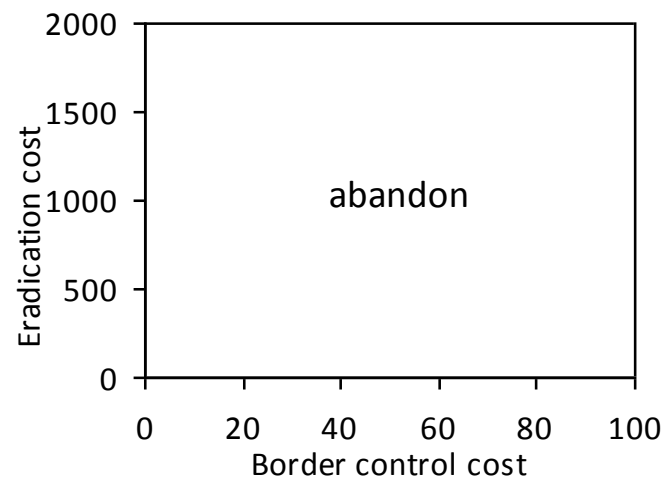

(B)

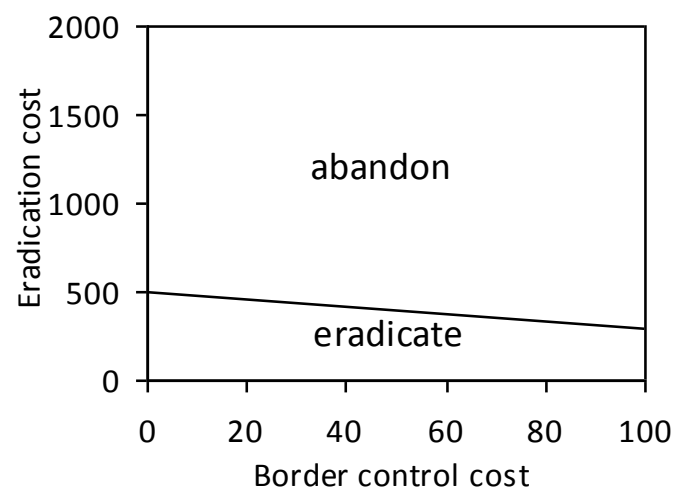

Fig. 3. Optimal long-run outcomes when the probabilities of spread, successful cell and border control are $20 \%$. The initial invasion is either in the middle (A), in the corner $(B)$ or on the edge of the landscape $(C)$.

\section{Optimal long-run outcomes for different probabilities of spread}

Here we analyze how change in the probability of spread affects the optimal long-run outcomes when the probability of successful cell and border control are deterministic. This analysis focuses on the case where initial infestation is on the edge of the landscape. The optimal long-run outcome does not change significantly when the probability of spread decreases from $100 \%$ (Fig. 4A) (i.e. deterministic case) to $80 \%$ (Fig. 4B). When the probability of spread reduces from 1 to 0.8 , marginal cost of eradication relative to their marginal benefit decline slightly. Thus, eradication becomes slightly more feasible, and so it becomes optimal in a few more cases because slightly less control effort is needed to contain or eradicate. Similarly, the set 
of cases for which containment is optimal expands slightly when the probability of spread decreases to $80 \%$.

(A)

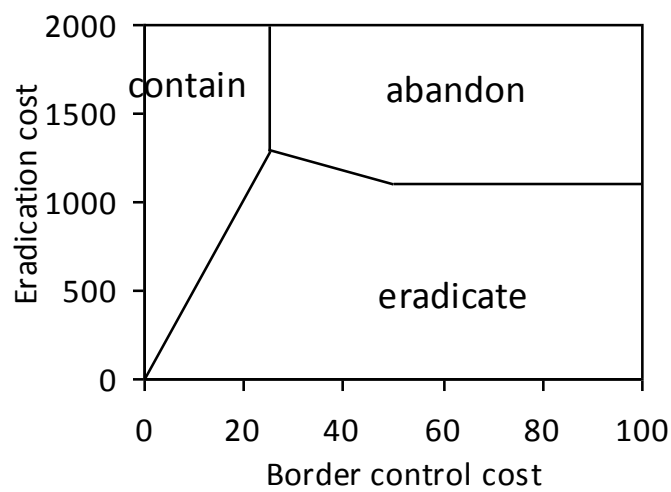

(C)

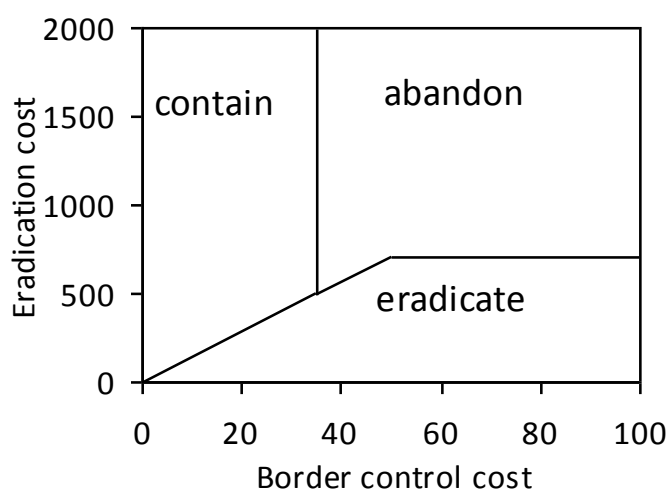

(B)

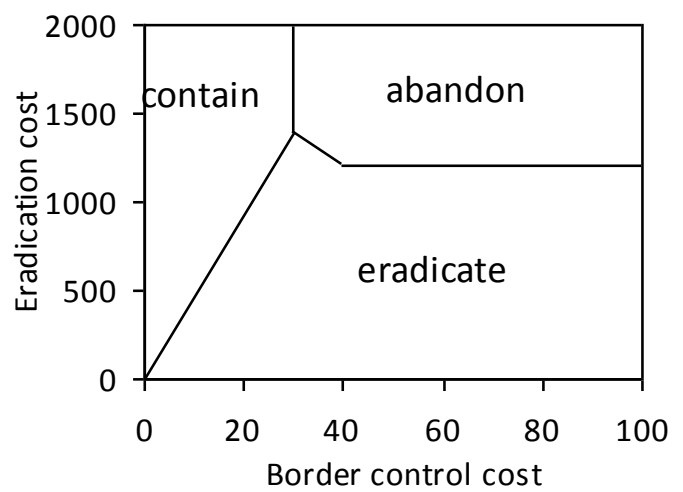

Figure 4. Optimal long-run outcomes when the probability of spread is $100 \%$ (A), $80 \%(\mathrm{~B})$ or $20 \%(\mathrm{C})$. Cell control and border control are deterministic and the initial infestation is on the edge of the landscape.

A decrease of the probability of spread to $20 \%$ (Fig. 4C), reduces the economic damages caused by invasive species at an earlier stage of invasion because of the slower rate of spread. This reduces the marginal benefit of eradication, resulting in a smaller set of scenarios for which eradication is optimal. On the other hand, it is much easier to contain the infestation when the probability of spread decreases to $20 \%$. Therefore, containment becomes optimal for a larger set of scenarios. 
Optimal long-run outcomes for different probabilities of successful cell control Fig. 5A-C show how different assumptions about the probability of successful cell control affect optimal long-run outcomes. In these solutions, spread and border control are deterministic and initial infestation is on the edge of the landscape. Decreasing the probability of successful cell control to $80 \%$ (Fig. 5B) does not have a significant impact on the optimal long-run outcome as compared with deterministic cell control (Fig. 5A). 
(A)

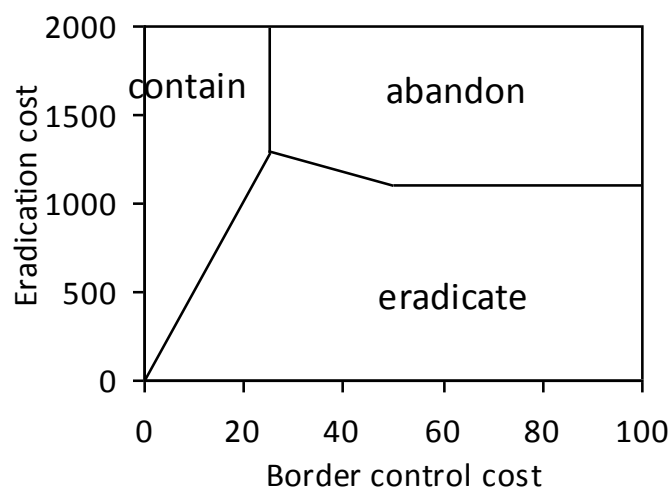

(C)

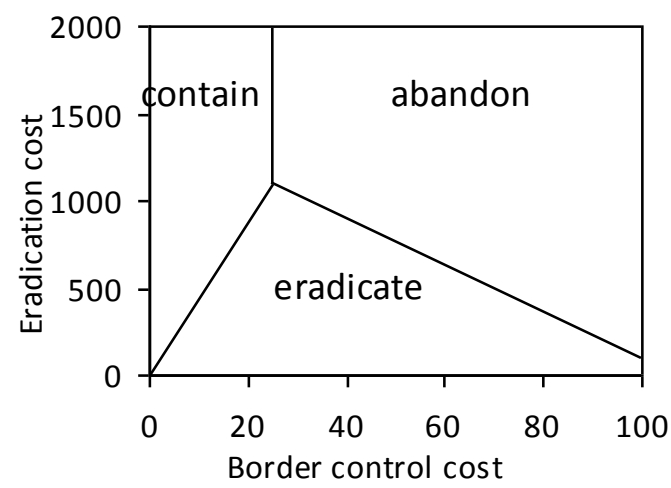

(B)

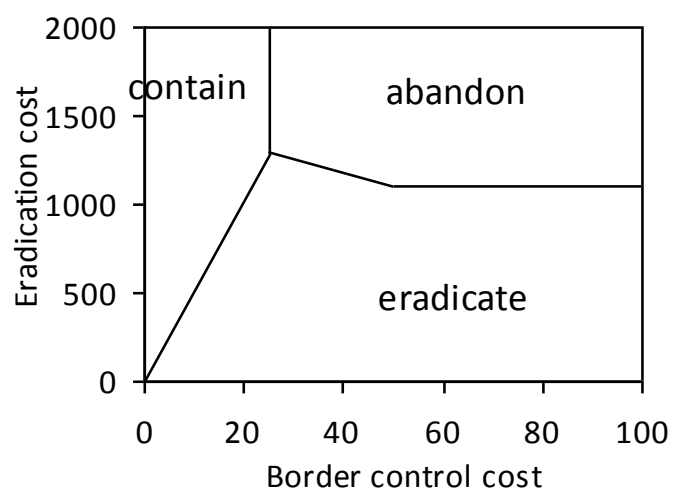

Fig. 5. Optimal long-run outcomes when the probability of cell control is $100 \%$ (A), $80 \%$ (B) or $20 \%$ (C). Spread and successful border control are deterministic and initial infestation is on the edge of the landscape.

However, when the probability of successful cell control deceases to $20 \%$, eradication is optimal only at a lower eradication cost (Fig. 5C) because in many cases when cell control has been applied, eradication is not achieved. Containment remains optimal for a similar set of cases. However, border control contributes to eradication, so as the cost of border control increases, the set for which eradication is optimal decreases.

\section{Optimal long-run outcomes for different probabilities of successful border control}

The effects of change in the probability of successful border control on the optimal long-run outcomes are analyzed here. The probability of spread and 
successful cell control are deterministic and initial invasion is on the edge of the landscape. Fig. 6A presents the optimal long-run outcomes for deterministic case and Figs $6 \mathrm{~B}$ and $6 \mathrm{C}$ present results when border control is stochastic.

(A)

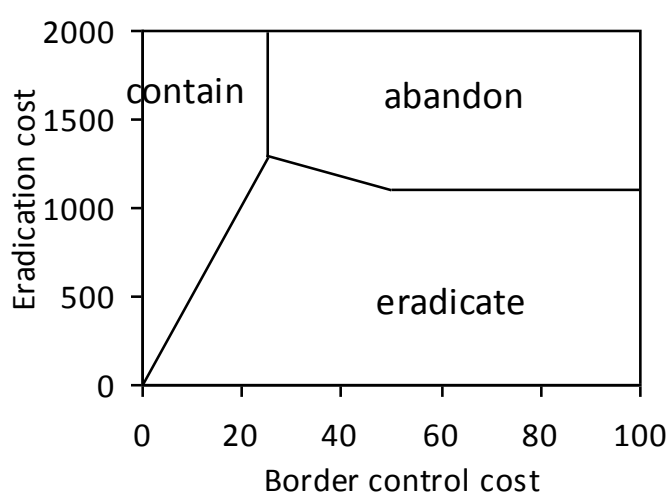

(C)

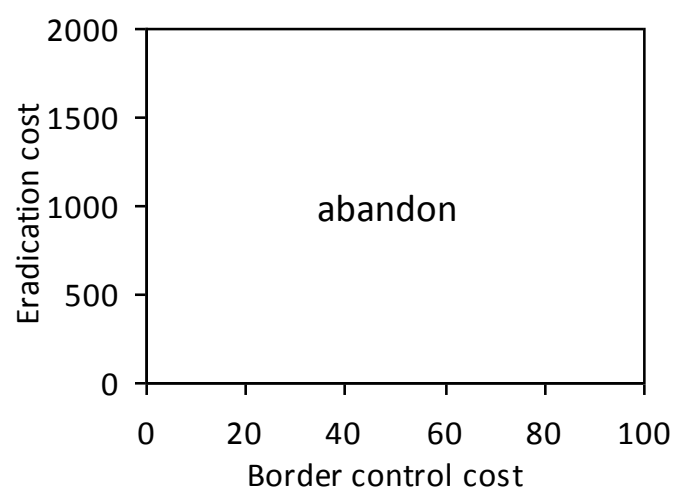

(B)

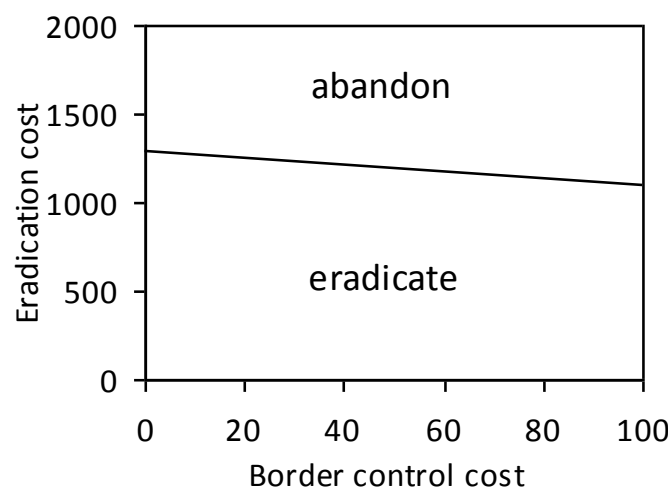

Fig. 6. Optimal long-run outcomes when the probability of border control is $100 \%$ (A), $80 \%$ (B) or $20 \%$ (C). Spread and successful cell control are deterministic and initial infestation is on the edge of the landscape.

As noted earlier, stochastic border control means that containment is no longer a feasible option at steady state. When the probability of successful border control decreases to $80 \%$ (Fig. 6B), eradication remains optimal for a similar range of eradication cost as when border control is deterministic. However, when the probability of successful border control decreases to $20 \%$, it is no longer optimal to eradicate at any eradication cost at steady state. This is because poor border control reduces the benefits of an eradication strategy. 
There is an interesting interaction between eradication cost and border-control costs in their impacts on optimal long-run outcome. Fig. $6 \mathrm{~b}$ shows that, for relatively high eradication costs (e.g. 1200), eradication is optimal when border-control cost is low. However, as border-control cost increases, abandonment of control becomes optimal even though eradication cost has remained unchanged. Thus, there is an interaction between border control and cell control. Here we present the dynamics of spread, cell control and border control for different eradication and border-control costs (Fig. 7). 
(A)

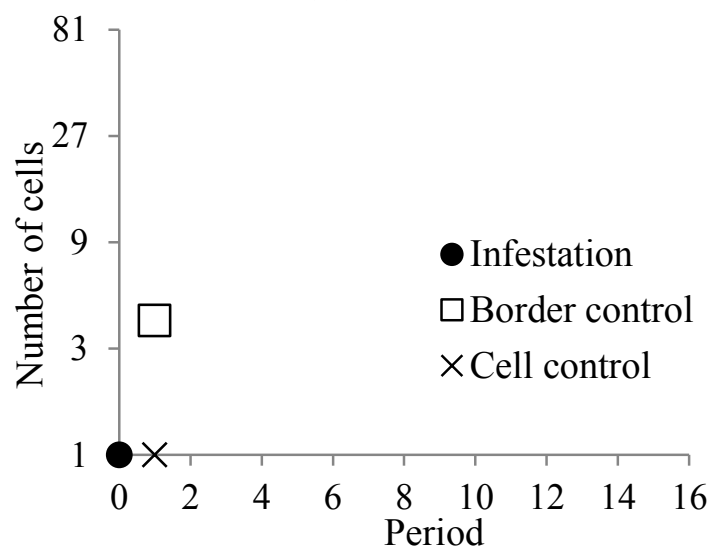

(C)

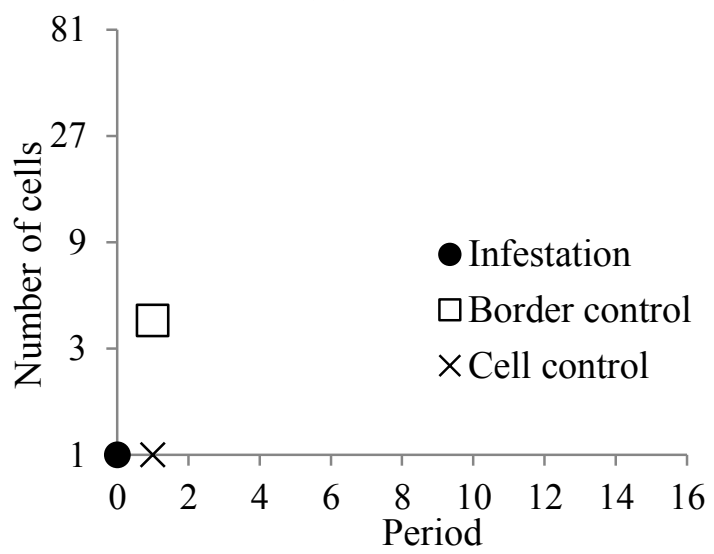

(D)
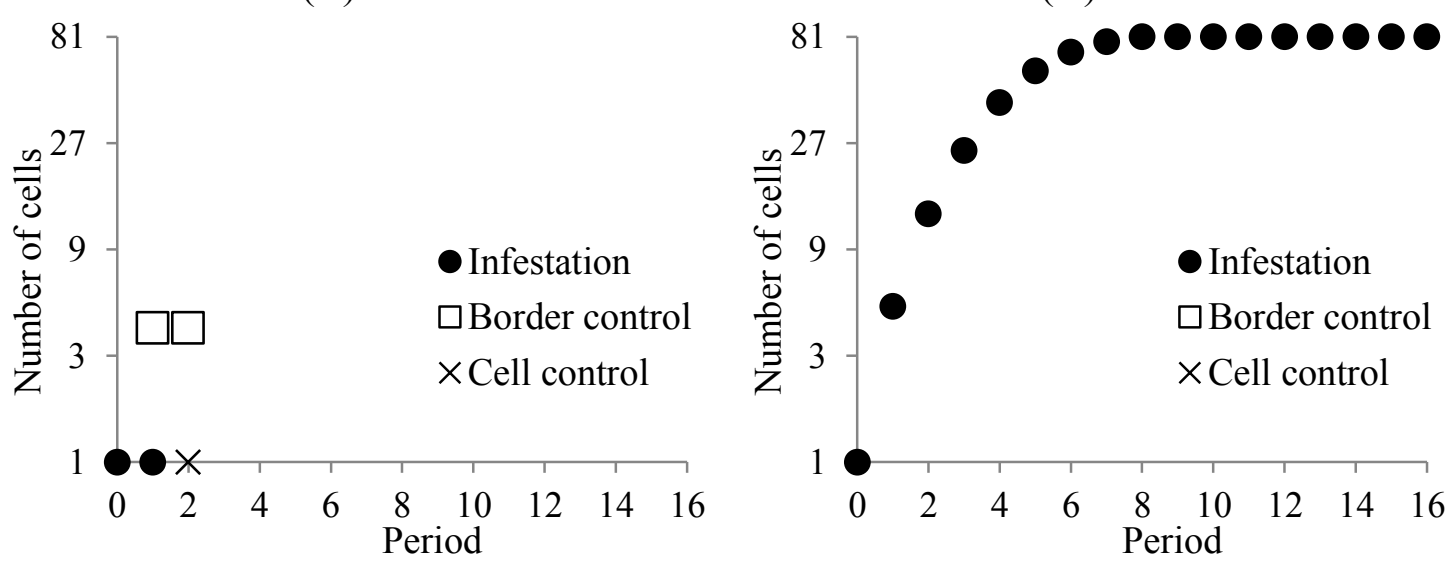

(E)

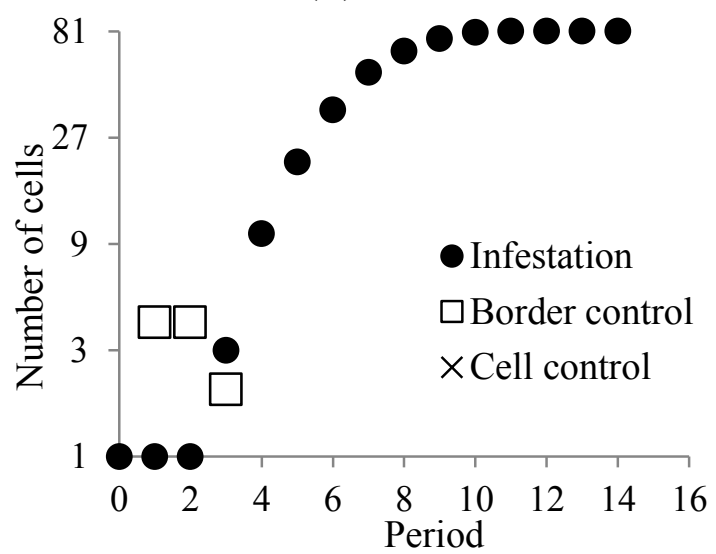

(F)

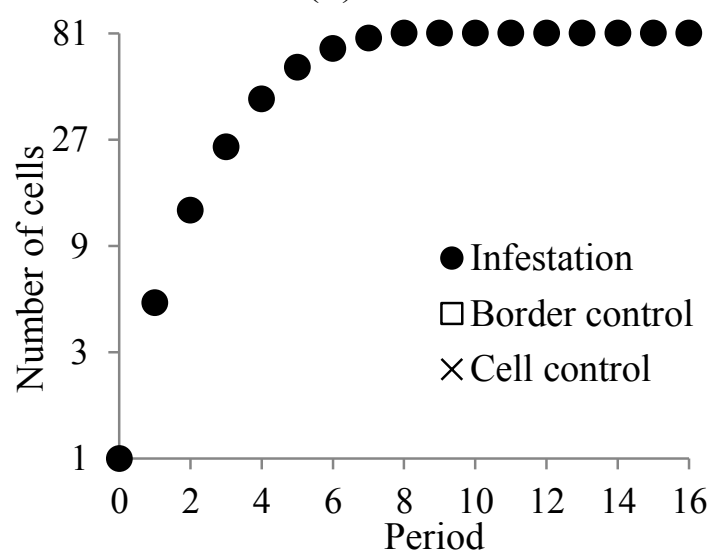

Figure 7. Dynamics of invasive species spread, border control and cell control under optimal dynamic strategies when initial infestation is on the edge of the landscape. Cell control and spread is deterministic and probability of successful border control is $80 \%$. Eradication costs (ec) and border-control costs (bc) for each panel are as follows: A) ec $=200$, and $b c=10$; B) ec $=200$, and $b c=70 ;$ C) ec $=1200$, and $b c=10$; D) $\mathrm{ec}=1200$, and $\mathrm{bc}=70$; E) ec $=1600$, and $\mathrm{bc}=10 ; \mathrm{F}) \mathrm{ec}=1600$, and $\mathrm{bc}=70$. 
Fig. 7a shows that it is optimal to apply cell control and border control in order to eradicate invasive species in the first period when cell and border-control costs are low. Eradication remains optimal even if border-control cost increases by 7 times. Border control is applied in order to avoid the spread of invasive species (Figure 7b).

For relatively high levels of eradication cost (e.g. 1200), optimal control depends on the magnitude of border-control cost. When border-control cost is low, it is optimal to contain invasive species in years 1 and 2 and apply cell control in the second year in order to eradicate invasive species (Figure 7c). In this case, control of invasive species is delayed till the second year, in part to benefit from discounting of delayed large costs. However, for higher levels of border-control costs, it is not optimal to delay the spread using border control. In this case, it becomes too expensive to apply any control and abandonment becomes the optimal long-run outcome (Figure $7 \mathrm{~d})$.

When cell-control cost is very high (e.g. 1600), it is not optimal to apply cell control so the invasive species eventually spreads over the entire landscape. For very high cell-control costs, if border-control cost is low, it is optimal to apply border control for 3 years in order to delay the spread of invasive species and reduce the present value of damages caused by invasive species (Figure 7e). However, when both border control and cell-control costs are very high, it is optimal to abandon control for the entire time horizon.

\section{Trajectory of invasive species and optimal control}

Fig. 8 presents the trajectory of the invasive species and control for different initial locations of invasive species in the landscape when probability of successful border control is $80 \%$. Although containment is not optimal at steady state, it is optimal to 
apply border control at the initial stage of infestation where invasive species has not yet taken over a large area.

(A)

(B)
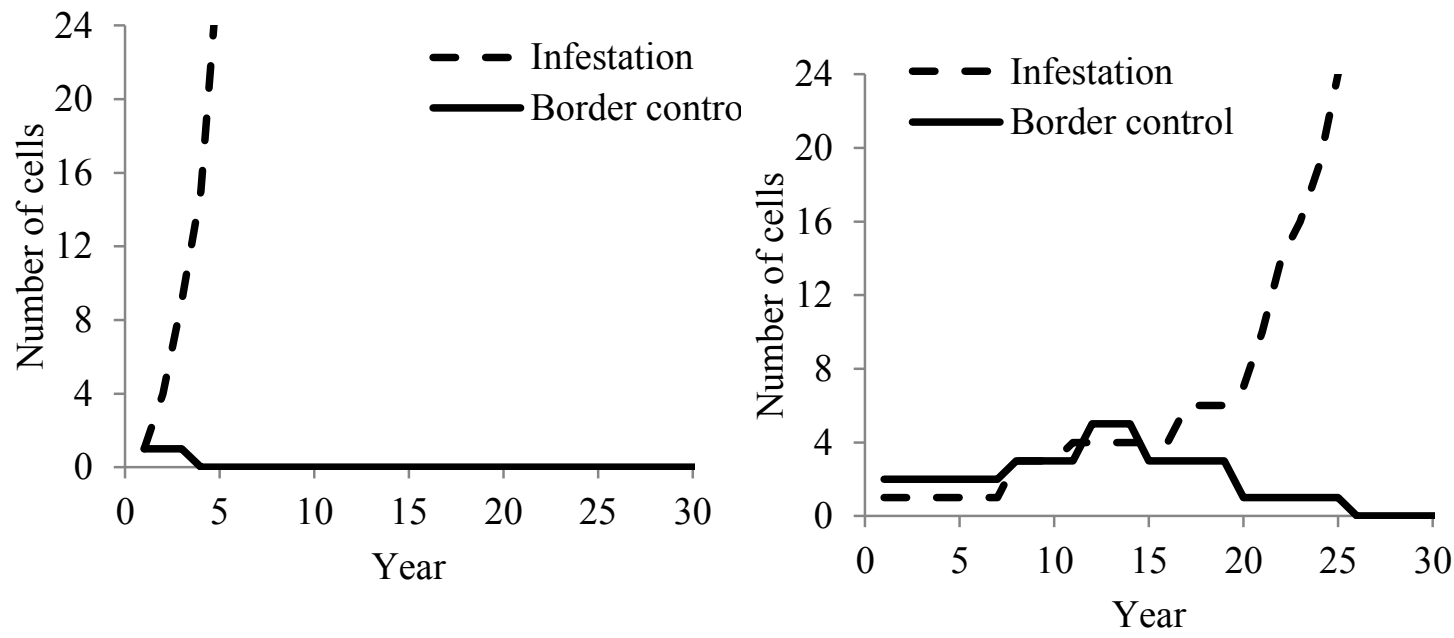

(C)

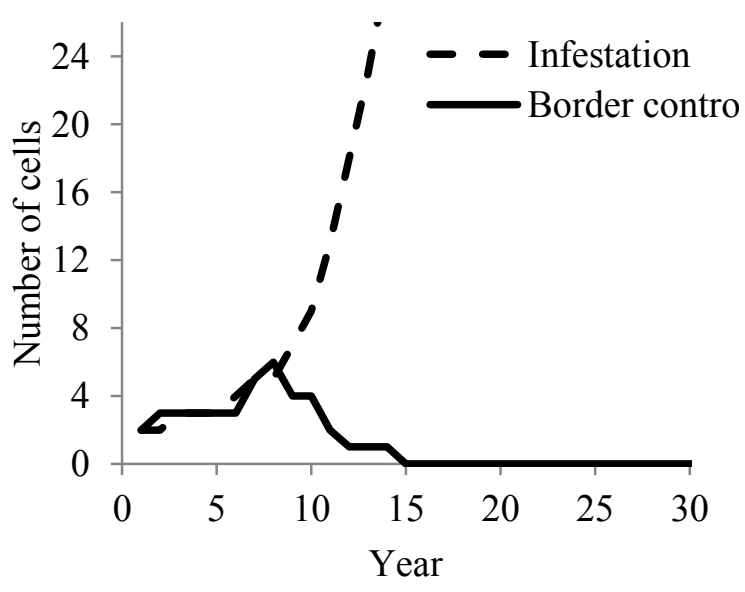

Fig. 8: Dynamics of invasive species and control when the probability of successful border control is $80 \%$ and the probability of spread and successful cell control is $100 \%$, when A) the initial infestation is in the middle, B) initial infestation is in the corner and C) initial infestation is on the edge of the landscape.

When the initial infestation is in the middle of the landscape, provided it is sufficiently small in size, it is optimal to apply border control. For example, in the scenario in Figure $8 \mathrm{~A}$, that size is about 9 cells. After three years, the infestation has spread beyond 9 cells, and border control is no longer optimal. The central location of infestation together with stochasticity in border control increases the chance of spread 
even when the control is applied. Therefore, border control is not cost-effective for larger infestation size. However, when the initial infestation is in the corner or edge of the landscape, the invasive species has fewer bordering cells over which it can spread and the stochasticity in border control has a smaller impact on spread (Fig. 8B and 7C). Therefore, it becomes optimal to apply border control for a longer period of time and for a larger infestation area. When initial infestation is in the corner of the landscape it is optimal to apply border control whilst the invasive species infests less than 24 cells, which is does until year 25 (Fig. 8B). The rate of spread for infestation on the edge is higher than infestation on the corner; therefore, when the initial infestation is on the edge of the landscape, it is optimal to apply border control whilst invasive species infests less than 23 cells in the landscape (i.e. for 12 years).

Economic losses due to a strategy resulting in suboptimal long-run outcome

Strategies resulting in suboptimal long-run outcomes would lead to in economic losses. The magnitude of these losses depends on the control costs and increase in damages when the suboptimal long-run outcome is achieved. To illustrate this, we present optimal and suboptimal outcomes where the probability of spread is $80 \%$. Fig. 9A and 9B represents optimal and suboptimal long-run outcomes, respectively. The percentage increase in net present value of economic losses (i.e. the sum of damages caused by invasion and control costs) due to choosing a suboptimal outcome is shown in Fig. 9B. 
(A)

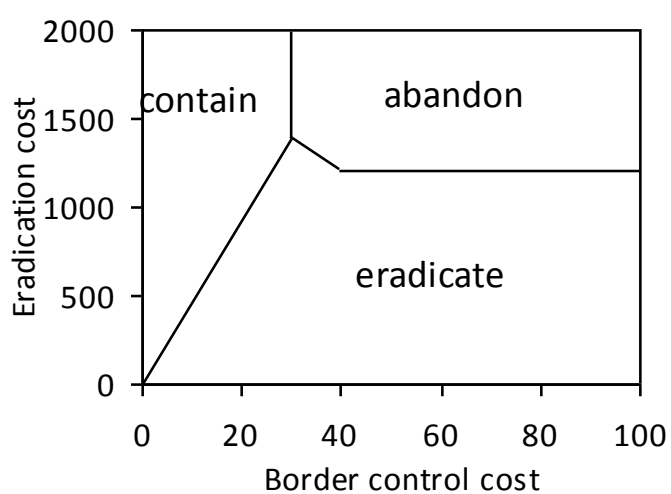

(B)

eradicate

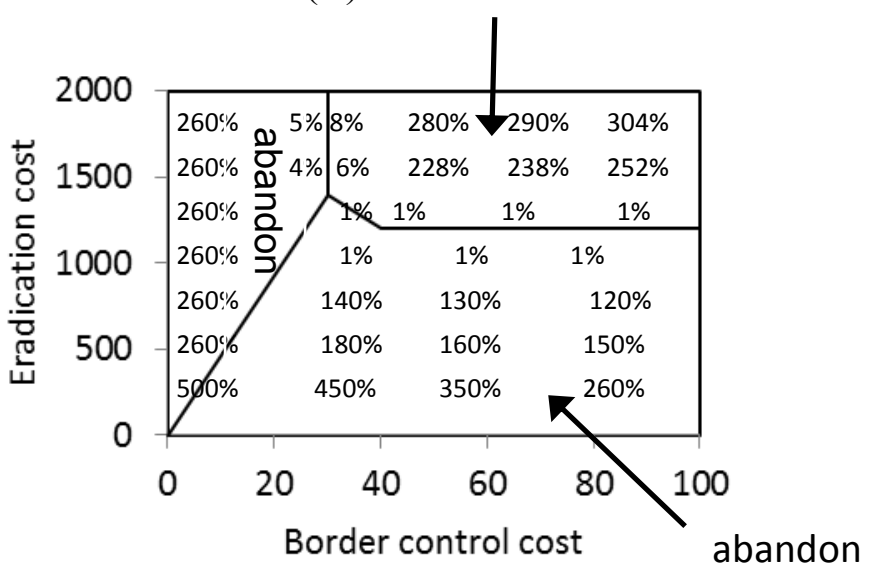

Fig. 9. Optimal long-run outcomes (A) and sub-optimal long-run outcomes (B) when the probability of spread is $80 \%$, cell control and border control are deterministic and the initial infestation is on the edge of the landscape. Numbers in graph (B) show the increase in the summed present value of costs due to adopting the sub-optimal strategy.9

The cost of adopting a strategy resulting in a suboptimal outcome varies depending on eradication cost and border-control cost. Fig. 9B indicates the particular sub-optimal outcomes that are compared to the optimum. For example, when eradication is the optimum, abandonment is the illustrative suboptimal outcome. Results show that costs are very sensitive to adoption of a strategy resulting in a sub-optimal outcome, more than doubling in many scenarios. For outcomes close to the original "abandon" boundary, costs are low (and are zero at the boundary, by definition). However, they increase rapidly as we move away from that boundary.

\section{Conclusions}

In this study we have analyzed optimal strategies to deal with invasive species in a stochastic, spatial, dynamic, setting. We have extended the work of Espanchin-Niell and Wilen (2012) by introducing stochasticity to a spatial dynamic process in an optimization formwork. Results showed that stochasticity and spatial location of initial infestation play important roles in determining the optimal strategy. 
We confirm the finding of Espanchin-Niell and Wilen (2012) that in the deterministic case, it is more likely to be optimal to eradicate or contain a species when the invasion is in the corner or on the edge as compared to the case where invasion is in the middle of the landscape. However, results show that in the stochastic case and for low probabilities of successful border control and cell control, it is not optimal to eradicate unless the invasion is in the corner of landscape.

Even small decreases in the probability of successful border control mean that containment is not a feasible strategy at steady state. However, use of border controls is an important part of the transitional strategy in many scenarios. It either contributes to slowing the spread of the invasive species, or to the achievement of its eradication.

As the probability of spread decreases, it takes longer for the invasion to cover the land and economic damages become smaller. Thus, economic benefits of control become smaller and for some ranges of parameter values abandonment can replace containment and containment can replace eradication. We also have shown that when the probability of successful cell control deceases to $20 \%$, it is optimal to eradicate only at a low eradication cost.

The study has important implications for public agencies responsible for management of invasive species. Results reinforce that there is not a uniform recommendation regarding the optimal strategy - it varies depending on the cost of border control, the cost of local pest removal, and the probabilities associated with various stochastic variables. Attempts to control invasive pests are not always worthwhile. Abandonment of such efforts is relatively likely to be optimal in cases where control costs are high, where the probability of successful border control is low, and where the invasion commences within the main body of the region, rather than from its regional boundary. 
Consideration of stochasticity in spread and/or control of the invasive species can have large impacts on the recommended strategies. It means that abandonment is more likely to be optimal, and that containment is not feasible in the long-run, although it can optimal in the short run. A failure to account for stochasticity may lead to investment in strategies that are not economically justified. 


\section{References:}

Aadland, D., C. Sims, and D. Finnoff. 2015. Spatial dynamics of optimal management in bioeconomic systems. Computational Economics 45: 454-577.

Albers, H., C. Fischer, and J. Sanchirico. 2010. Invasive species management in a spatially heterogeneous world: effects of uniform policies. Resource and Energy Economics 32: 483-499.

Bhat, M. G., R. G. Huffaker, and S.M. Lenhart. 1993. Controlling forest damage by dispersive beaver populations: centralized optimal management strategy. 347 Ecological Applications 3: 518-530.

Bogich, T., and K. Shea. 2008. A state-dependent model for the optimal management of an invasive metapopulation. Ecological Application 18: 748-761.

Brock, W., and A. Xepapadeas. 2004. Spatial Analysis: Development of Descriptive and Normative Methods with Applications to Economic-Ecological Modelling. University of Wisconsin, Department of Economics SSRI Working Paper No. 17, 2004.

Brock, W., X. Xepapadeas. 2008. Diffusion-induced instability and pattern formation in infinite horizon recursive optimal control. Journal of Economic Dynamics and Control 32: 2745-2787.

Burnett, K. M., B. A. Kaiser, and J. Roumasset. 2007. Invasive species control over space and time: miconia calvescens on Oahu, Hawaii. Journal of Agricultural and Applied Economics 39: 125- 132.

Chalak, M., and D.J. Pannell. 2012. Optimising control of an agricultural weed in sheep-production pastures. Agricultural Systems 109: 1-8. 
Cook, T., A. Storrie, and R. Medd. 1999. Selective spray-topping: Field testing of a new technique for reducing wild oat seed production. Pages 53-56 in Proceedings of the 12th Australian Weeds Conference. Hobart, Australia.

Costello, C., M. Springborn, C. McAusland, A. Slow. 2007. Unintended biological invasions: Does risk vary by trading partner? Journal of Environmental Economics and Management 54: 262-276.

Costello, C., and S. Polasky. 2008. Optimal har 365 vesting of stochastic spatial resources. Journal of Environmental Economics and Management 56: 1-18.

Ding, W., L., J. Gross, K. Langston, S. Lenhart, and L. A. Real. 2007. Rabies in raccoons: optimal control for a discrete time model on a spatial grid. Journal of Biological Dynamics 1: 379-393.

Eiswerth, M. E., and G. C. van Kooten. 2002. Uncertainty, economics, and the spread of an invasive plant species. American Journal of Agricultural Economics $1317-1322$.

Epanchin-Niell, R. S., and J. E. Wilen. 2012. Optimal spatial control of biological invasions. Journal of Environmental Economics and Management 63: 260 270.

Finnoff, D., A. Potapov, M. A. Lewis. 2010. Control and the management of a spreading invader. Resource and Energy Economics 32: 534-550.

Fiori, E., M. Mazzotti, F. Guerrini, and R. Pistocchi. 2013. Combined effects of the herbicide terbuthylazine and temperature on different flagellates from the Northern Adriatic Sea. Aquatic Toxicology 128: 79-90.

Grevstad, F. S. 2005. Simulating control strategies for a spatially structured weed invasion: Spartina alterniflora (Loisel) in Pacific Coast estuaries. Biological Invasions 7(4): 665-677. 
Grice, A. C. 2006. Commercially valuable weeds: can we eat our cake without choking on it? Ecological Management and Restoration 7(1): 40-44.

Grice, A. C., J. R. Clarkson, M. H. Friedel, K. Ferdinands, and S. Setterfield.2010. Containment as a strategy for tackling contentious plants. In Proceedings of the 17th Australasian Weeds Conference, ed. SM Zydenbos pp. 486-489.

Hartley, S., R. Harris, and P. J. Lester. 2006. Quantifying uncertainty in the potential distribution of an invasive species: climate and the Argentine ant. Ecology Letters 9(9): 1068-1079.

Higgins, S. I., D. M. Richardson, and R. M. Cowling. 2000. Using a dynamic landscape model for planning the management of alien plant invasions. Ecological Applications 10(6): 1833-1848.

Hof, J.1998. Optimizing spatial and dynamic population-based control strategies for invading forest pests. Natural Resource Modeling 11: 197-216.

Huffaker, R. G., M.G. Bhat, S.M. Lenhart. 1992. Optimal trapping strategies for diffusing nuisance-beaver populations. Natural Resource Modeling 6: 71-97.

Hyder, A., B. Leung, and Z. Miao. 2008. Integrating data, biology, and decision models for invasive species management: application to leafy spurge (Euphorbia esula). Ecoolgy and Society 13(2): 12.

Latimer, A. M., S. Banerjee, Jr. H. Sang, E. S. Mosher, Jr J. A. Silander. 2009. Hierarchical models facilitate spatial analysis of large data sets: a case study on invasive plant species in the northeastern United States. Ecology Letter 12, $144-154$.

Madafiglio, G. P. 2002. Population Management of Raphanus raphanistrum L. (Wild Radish) by Regulating Seed Production. Ph.D. thesis. University of Western Sydney, Penrith South, Australia. P. 208. 
Manne, A. S. 1999. "Equity, efficiency, and discounting.” In P. R. Portney and J. P. Weyant, eds. Discounting and integrational equity. Resourced for the Future, Washington D.C. pp. 111-129.

Nordhaus, W. 1994. Managing the global commons: the economics of climate change. Cambridge, Massachusetts: MIT Press.

Odom, D. I. S., O.J. Cacho, J.A. Sinden, and G.R. Griffith. 2003. Policies for the management of weeds in natural ecosystems: the case of scotch broom (Cytisus scoparius, L.) in an Australian national park, Ecological Economics

44: 119-135.

Olson, L., and S. Roy. 2002. The economics of controlling a stochastic biological invasion. American Journal of Agricultural Economics 84: 1311-1316.

Olson, L. J., and S. Roy. 2010. Dynamic 389 sanitary and phytosanitary trade policy. Journal of Environmental Economics and Management 60: 21-30.

Potapov, A. B., and M. A. Lewis, 2008. Allee effect and control of lake system invasion. Bulletin of Mathematical Biology 70: 1371-1397.

Rouget, M. and D. M. Richardson. 2003. Inferring process from pattern in plant invasions: a semimechanistic model incorporating propagule pressure and environmental factors. American Naturalist 162: 713-724.

Sanchirico, J., and J. Wilen. 2005. Optimal spatial management of renewable resources: matching policy scope to ecosystem scale. Journal of 395 Environmental Economics and Management 50: 23-46.

Sanchirico, J., and J. Wilen. 2007. Sustainable use of renewable resources: implications of spatial-dynamic ecological and economic processes, International Review of Environmental and Resource Economics 1: 367-405. 
Sanchirico, J., H. Albers, C. Fischer. 2010. Coleman, Spatial management of invasive species: pathways and policy options. Environmental and Resourc Economics 45: $517-535$.

Saphores J. D. M. 2000. The economic threshold with a stochastic pest population: a real options approach. American Journal of Agricultural Economics 82: 541555.

Wilen, J., 2007. Economic of spatial-dynamic processes. American Journal of Agricultural Economics 89: 1134-1144. 